\title{
artículos
}

\section{Trabajos y labores de carpinteros, orfebres y bordado- res sevillanos en la provincia de Málaga durante la segunda mitad del siglo XVI}

\author{
Antonio Joaquín Santos Márquez \\ Universidad de Sevilla
}

RESUMEN

En este artículo se dan a conocer cuatro noticias inéditas sobre una serie de encargos realizados a diferentes artistas sevillanos durante la segunda mitad del siglo XVI, los cuales iban destinados a varias iglesias de la provincia de Málaga que históricamente pertenecieron al antiguo territorio del Arzobispado de Sevilla. Concretamente hablamos de las poblaciones que conforman actualmente la comarca del Guadalteba y los encargos se centran en trabajos de carpintería de lo blanco, platería y bordados.

PALABRAS CLAVE: Arquitectura Religiosa/ Carpinteros/ Orfebres/ Bordadores/ siglo XVI/ Málaga/ Sevilla.

Works and labors of carpenters, goldsmiths and sevillian embroiderers in the province of Málaga wine during the second half of the 16th century.

ABSTRACT

This article presents four documents of the Sevillian artists that they worked for the parishes of the malagueños towns of the former territory of the Archbishopric of Seville during the second half of the 16th century. We speak about the towns included in the region of the Guadalteba and on works of carpentry, silverwork and embroidery.

KEY WORDS: Religious Architecture/ Carpenters/ Goldsmiths/ Embroiderers/ XVIth century, Málaga/ Sevilla.

La presencia de artistas sevillanos en la provincia de Málaga no es algo novedoso. Desde la conquista cristiana, las relaciones artísticas con la capital hispalense fueron constantes, siendo bastante fluidos la comunicación y el trasvase de ideas y artistas durante la Edad Moderna, como igualmente sucedió con otras capitales y provincias andaluzas. Pero bien es cierto que ello se hace más evidente en los territorios malagueños que históricamente estuvieron vinculados desde el punto de vista jurídico y religioso a Sevilla. Hablamos de parte de la zona noroeste de la provincia malagueña, concretamente del actual Arciprestazgo de Campillos, que en 1833 dejó de pertenecer al Antiguo Reino de Sevilla, y hasta 1958, la hoy denominada también comarca del Guadalteba, formó parte del extenso Arzobispado Hispalense ${ }^{1}$. En con-

* SANTOS MÁRQUEZ, Antonio Joaquín: "Trabajos y labores de carpinteros, orfebres y bordadores sevillanos en la provincia de Málaga durante la segunda mitad del siglo XVI", en Boletín de Arte, n $30-31$, Departamento de Historia del Arte, Universidad de Málaga, 2009-2010, págs. 13-31. Fecha de recepción: Marzo de 2009. 1 ALDEA, Q., MARÍN, T., VIVES, J.: Diccionario de Historia Eclesiástica de España. Madrid, Instituto Enrique Flórez, 1972-1987, Vol. II, pág. 1399. 


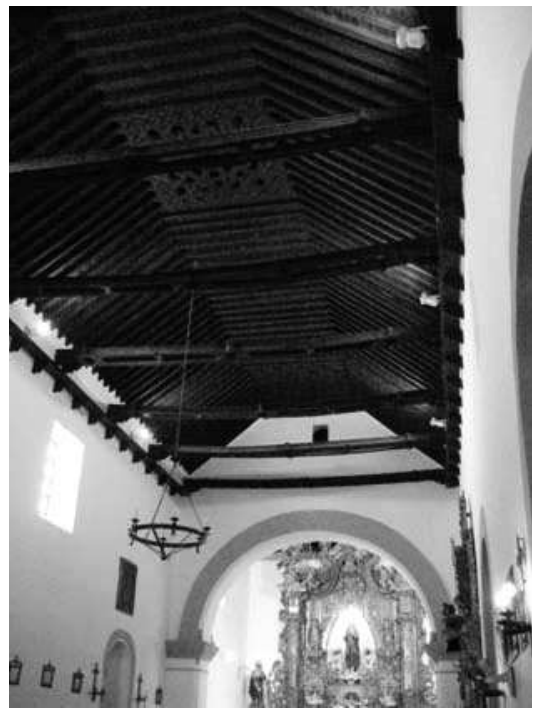

1. Nave principal de la iglesia parroquial de la Inmaculada Concepción de Almargen.

creto son las poblaciones de Almargen, Ardales, Campillos, Cañete la Real, Peñarrubia, Sierra de Yeguas y Teba, en cuyos templos parroquiales especialmente se advierte la actuación de los principales arquitectos sevillanos de los siglos XVI al $\mathrm{XVIII}{ }^{2}$. Desgraciadamente el paso del tiempo y la última guerra mermó en mucho el arte mueble de estas iglesias, si bien contaron con un importante conjunto de obras de arte, salidas en su mayoría de los más afamados talleres sevillanos, como se puede constatar a través de la documentación ${ }^{3}$. Por ello queremos ahora por nuestra parte aumentar más si cabe el conocimiento de esta presencia histórica sevillana en la provincia malagueña, sacando a la luz una serie de documentos inéditos vinculados con las artes aplicadas y decorativas 4 . Noticias que además nos permiten

2 CAMACHO, R.: Málaga Barroca: arquitectura religiosa de los siglos XVII y XVIII. Málaga, Colegio de Arquitectos, Universidad de Málaga, 1981, págs. 503-530.

3 Ejemplos de la actividad de estos años de artistas sevillanos en la zona pueden ser los siguientes: el retablo y sagrario de la parroquia de Ardales, encargado en 1579 al entallador Juan de Figueroa y traspasado en 1581 a Miguel Adán y a Juan de Oviedo; obra que finalmente no se comenzaría hasta 1588 cuando de nuevo se hacía cargo de la misma Juan de Figueroa y Juan de Saucedo. En 1588 Juan Bautista Vázquez se comprometía a fabricar un monumento, continuado por Bartolomé Muñoz en 1595, para la iglesia de Cañete la Real; LÓPEZ MÁRTÍNEZ, C: Desde Martínez Montañés hasta Pedro Roldán, Sevilla, Rodríguez, Jiménez y Ca., 1932, págs. 47, 84; Desde Jerónimo Hernández hasta Martínez Montañés. Sevilla, Rodríguez, Jiménez y Ca., 1929, págs. $120,200,249$. Asimismo pueden servirnos de ejemplo el sagrario y retablo mayor que realizó Diego López Bueno para la iglesia de Campillos entre 1629 y 1632, y la policromía de estas obras y del monumento para Teba por Pablo Legot al año siguiente; LÓPEZ MARTíNEZ, C.: Arquitectos, escultores y pintores vecinos de Sevilla. Sevilla, Rodríguez, Jiménez y C ${ }^{a}$., 1928, pág. 81, 85; VV.AA.: Documentos Varios, Documentos para la Historia del Arte en Andalucía, Sevilla, Laboratorio de Arte, 1928, t. II, págs. 148, 304.

4 Utilizamos este término para englobar a todas estas expresiones artísticas siguiendo el criterio establecido por don Antonio Bonet Correa en la coordinación de la obra Historia de las Artes Aplicadas e Industriales en 
poner nombre y apellidos a creaciones que aún perviven en estos templos y que hasta el día de hoy guardaban celosamente su anonimato. Concretamente, se trata de la documentación relativa a la construcción de la armadura de la nave central de la iglesia parroquial de Almargen, afortunadamente conservada, al bordado de un paño de difuntos para el templo mayor de Cañete la Real, y a dos obras de platería labradas por los plateros de la Catedral de Sevilla para la parroquia y el convento franciscano de Teba.

Comenzando pues nuestro recorrido por orden cronológico, la creación más antigua de todas las referidas es la armadura mudéjar de la nave principal de la parroquia de la Concepción de la villa de Almargen, cuyos trámites para su contratación se iniciaron en pleno proceso constructivo del templo, durante el tercer cuarto del siglo XVI [1] ${ }^{5}$. Concretamente todo comenzó el 13 de marzo de 1569, momento en el cual se procedió a la divulgación de las condiciones para su hechura y su subasta posterior entre los oficiales que acudieron a tal evento ${ }^{6}$. Ello transcurrió en las casas de audiencia y morada del Provisor del Arzobispado hispalense don Cristóbal de Padilla, deán y canónigo de la Catedral de Sevilla, personaje que determinó como máxima autoridad la necesidad de esta nueva obra, ya que la sede episcopal se encontraba vacante en estos momentos ${ }^{7}$. Para esta cita comparecieron ocho carpinteros, ávidos de participar en la subasta que se iniciaría una vez se leyeran las condiciones que había elaborado Rodrigo Osorio, Carpintero de las Fábricas del Arzobispado, y que describían la armadura que debía cubrir la nave principal y única de la iglesia, la cual medía aproximadamente 26 varas de largo por 9 de ancho (21,71 x 7,51 metros). Estas condiciones constituyen una fuente de información importantísima, ya que nos permiten hacernos una idea bastante exacta de lo que en origen se había ideado y, en este caso concreto, compararlo con lo que luego fue su resultado final ${ }^{8}$. Éstas tienen un claro orden estructural, iniciándose en las disposiciones relativas al arranque y soporte del enmaderado para concluir con la descripción de los elementos de este último.

España. Manuales de Arte Cátedra, Madrid, 1994 (tercera edición).

5 Archivo Histórico Provincial de Sevilla. Sección de Protocolos Notariales de Sevilla (a partir de este momento AHPSe. SPNSe.): Legajo 118, oficio 1, libro $2^{\circ}$ de 1569, ff. 878 v.-879 r.. Documento $1^{\circ}$

6 Trámites del contrato que coinciden con los empleados en otros ámbitos artísticos, y que fueron recogidos en las Constituciones del Arzobispado de Sevilla, hechas y ordenadas por el llustrísimo y Reverendísimo Sr. D. Fernando Niño de Guevara, Cardenal y Arzobispo de la Santa Iglesia de Sevilla, en el Sínodo que se celebró en su Catedral en el año de 1604. PALOMERO PÁRAMO, J. M.: El retablo sevillano del Renacimiento: análisis y evolución (1560-1629). Sevilla, Diputación de Sevilla, 1983, pág. 13.

7 La contratación de esta obra viene a coincidir con el periodo entre la muerte del arzobispo Fernando Valdés, el 9 de diciembre de 1568, y el gobierno de Gaspar de Zúñiga y Avellaneda, que toma posesión de la sede hispalense el 13 de octubre de 1569, por ello alude al carácter vacante de la sede hispalense. ROS, C.: Los Arzobispos de Sevilla. Luces y sombras de la sede hispalense. Sevilla, 1986, págs. 146-147.

8 Para la comprensión de los términos empleados en el texto hemos utilizado las obras de AGUILAR, M. D.: Málaga Mudéjar. Arquitectura religiosa y civil. Málaga, Universidad de Málaga, 1979; La carpintería mudéjar en los tratados, Málaga, Universidad de Málaga, 1984, NUERE, E.: La carpintería de armar española, Madrid, Ministerio de Cultura, 1989. 
Así, en el primer capítulo se expone que sobre los muros parietales de la nave del templo se debían empotrar unos nudillos o tacos de refuerzo donde se ajustasen las soleras, o durmientes horizontales, sobre las que se asentaría la armadura. Estas soleras debían tener una ochava de grosor y una cuarta de ancho, más una pulgada de vuelo, mostrando en su desarrollo horizontal una moldura romana entre dos filetes, ornamentación que se completaría con el replano o cornisa superior, también de una pulgada, la cual iría adornada con un dentellón.

En la segunda condición se hace alusión a los estribos y tirantes que darían la solidez oportuna a la estructura. Se dice que a lo largo de toda la nave, desde los pies hasta el arco toral que da paso al presbiterio, se debían repartir a intervalos de dos varas $(1,67 \mathrm{~m}$.) los tirantes que cupieren. Estos se compondrían de una pareja de tableros con seis peinazos distribuidos por parejas en los extremos y en el centro; tablas que servirían para crear los lazos con que se unen las vigas de los tirantes, aumentando así la deseada estabilidad. Estas labores de lacerías describirían un signo tradicional en forma de estrella de ocho puntas en el centro, mientras que los extremos presentarían la mitad de un signo similar, entre los que debían ir además cuatro azafates, todo ello guarnecido con las respectivas aspillas, tabicas y ochavillos, atando sus perfiles a romo y agudo. Labor que debía estar embarrotada y embarbillada a cola de milano, siguiendo los usos y costumbres propios de la carpintería mudéjar.

Sobre las soleras y los tirantes se dispondrían los estribos de roble labrados por haz y canto, todo perfectamente sujeto con clavos para que este telar pudiera soportar la armadura de par y nudillo superior. Su estructura es descrita en la tercera condición, en la que se habla de un enmaderado a dos aguas sencillo, compuesto por los aludidos pares y nudillos con las medidas habituales, al cartabón los pares y al tercio los nudillos, además de su hilera superior, nervio central del armazón. Estas tablas debían además presentar sus perfiles regulados, y estar ensambladas a romo y agudo. Los espacios resultantes de la unión de estas vigas, tanto en los costados como en el almizate, serían ocupados por haldetas cuadradas compuestas por cintas y saetinos entrecruzados, echando sus medias cintas sobre las tabicas y quiebras del nudillo, todo bien sujeto a base de dos clavos por cada tablilla.

Igualmente se pedía que se utilizaran todas las tablas necesarias, bien labradas y cepilladas, y clavos de calidad, para su mayor lucimiento y vistosidad desde la nave. De hecho, se demandaba que en las partes superiores no visibles se empleasen maderas toscas, mientras que en las partes del asiento de los pares, el arrocabe, estuviesen perfectamente acabadas al igual que el resto de la armadura. $Y$ en la siguiente condición se reitera la necesidad de la utilización esmerada de las técnicas del labrado y cepillado de todas las maderas utilizadas para los pares o alfardas, nudillos y tirantes, se observasen las medidas de un grueso para las saetinas y un ancho las cintas, y que todo se llevase a cabo con sumo cuidado y perfección, alertando que si alguna cosa fuese innovada en la obra descrita, no llevara implícito un encarecimiento de su precio. 
Con respecto a las maderas que se debían utilizar, puestas por la fábrica, se pedía que fuesen el pino y el roble, habituales en estos trabajos. Toda esta madera se debía desalabear y arreglar para que los aserradores pudieran hacer bien su trabajo con la sierra francesa, el cual sería pagado por la fábrica, sin excederse en lo estipulado si no era mandado por el Provisor, ya que esta demasía correría a cargo del carpintero. Y además, éste no debía abandonar la obra desde el día en que la iniciare hasta que la terminare, pagando por día faltado dos ducados de multa, que serían descontados del montante total que se le daría cuando estuviese acabada la armadura, siendo estos dineros incautados para la fábrica parroquial. Pero si el incumplimiento lo cometiese la mayordomía en la entrega de los materiales y los maravedíes acordados, ésta igualmente sería penada con dos ducados a cobrar por el oficial carpintero. También se hace hincapié que las herramientas y las sogas serían puestas por este mismo maestro. $Y$ dentro de sus obligaciones, igualmente se encontraba la de abonar la fianza establecida al mayordomo de fábricas en los diez días siguientes a la adjudicación de esta empresa, so pena de mil maravedíes y la retirada del encargo. Además, le darían al maestro veinticinco docenas de tablas de pino de Flandes, cuarenta y dos pinos, y ocho vigas de roble, más la madera que tuviera necesidad, apartándola en las atarazanas sevillanas o en los talleres de carpintería de ribera ubicados en el Arenal de Sevilla.

Muy curiosa nos parece la antepenúltima condición relativa a las medidas de la nave a techar. En ella se aclara que las varas del ancho y el largo de la nave que habían sido dadas con anterioridad eran aproximadas, advirtiendo que si fuese mayor el espacio a cubrir se le pagara al maestro lo que le correspondiese por dicho trabajo, algo que creemos fue lo que finalmente sucedió. Sin olvidar tampoco que si sucediese lo contrario, se le restaría de lo estipulado en la subasta en proporción con la minoría apreciada en la nave de la iglesia. Y con respecto al pago, tal y como era tradición en los contratos episcopales, una vez depositada la fianza por el maestro, éste recibiría para comenzar su labor un tercio de su precio, cuando tuviesen terminados dos tercios de la obra recibiría el segundo pago y la última parte de este dinero en el momento en el que la armadura hubiese sido valorada por los especialistas que apreciasen su buena hechura, visita ésta última que debía ser costeada por ambas partes. Reservándose además el provisorato episcopal la autoridad de cobrarle las faltas e imperfecciones que finalmente tuviese el enmaderado. También el carpintero debía escriturar la obra con el mayordomo de las fábricas arzobispales y pagar al carpintero Rodrigo Osorio 24 reales por la elaboración de estas condiciones, 9 a la cofradía gremial de San José, y otros 2 reales al notario Jerónimo de Orbaja, en definitiva, un total de 35 reales que se le descontarían del primer pago.

Una vez leídas las condiciones se celebró la subasta de la obra con un precio de salida fijado por Osorio en 50.000 maravedíes. El primero en pujar fue Miguel de Vallón con 45.000 maravedíes, luego fue Cristóbal Jiménez con 40.000, siguiéndole Fernando Arias con 38.000, Juan Bautista con 36.000, Juan López con 34.000, Alonso Fernández con 32.000, nuevamente Miguel de Vallón con 30.000, Pedro de Arenillas 


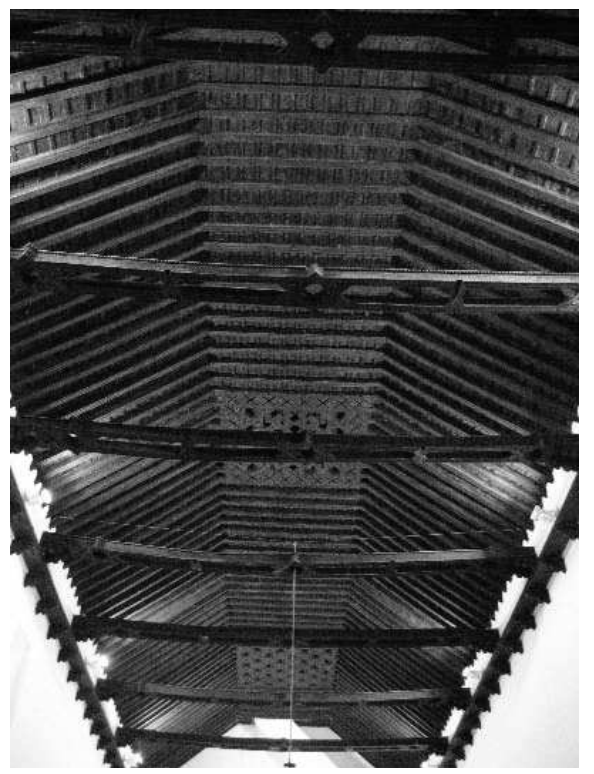

2. Armadura de la nave principal de la parroquia de la Inmaculada Concepción de Almargen, Juan Bautista, 1569.

con 28.000 maravedíes, Rodrigo Fuente con 26.500, otra vez Cristóbal Jiménez con 27.000, también Juan Bautista con 26.000, Pedro de Arenillas prueba de nuevo con 25.000, y finalmente le es adjudicada la obra al último postor, a Juan Bautista por la cifra de 24.000 maravedíes en la que se fijó la hechura de esta armadura.

Así pues, tras esta subasta, y tal y como se estipulaba en las condiciones, se escrituró el contrato y obligación de la obra el 21 de marzo, por parte del carpintero Juan Bautista y el mayordomo mayor de las fábricas arzobispales don Lázaro Martín de Coca y el Provisor del Arzobispado. En ella se comprometía el carpintero a observar todas las directrices descritas con anterioridad, constituyendo como su fiador a su hermano Pedro Alonso, del mismo oficio.

Y como dijimos en un principio, lo afortunado en este caso es que la techumbre realizada por el carpintero sevillano se conserva aún hoy en la actual parroquia de la Concepción de Almargen, una obra que además ya había sido incluida dentro de los trabajos de carpintería de este mismo periodo cronológico y que nos permite encuadrar también la construcción del templo en estos mismos años [2] ${ }^{9}$. Asimismo, es interesante comprobar como el resultado final fue ligeramente modificado con respecto a la planificación descrita como vamos seguidamente a analizar. No hay variación alguna en su estructura general donde se reproduce lo demandado, ya que la cubrición de la nave central se hace a través de una armadura de par y nudillo, recta

$\overline{9}$ AGUILAR, M. D.: Málaga Mudéjar...op. cit., pág. 172. 
en sus extremos, y con ocho tirantes dobles atando la cubierta. No obstante se aprecian diferencias sobre todo en las soleras y en el arrocabe. Las primeras se resuelven de manera muy sencilla, con un saliente filete o replano moldurado con canes de perfiles redondeados que nada tienen que ver con lo descrito en la primera condición del contrato. Posiblemente las reformas posteriores del templo, sobre todo en el siglo XVIII, provocaron dicho cambio y también la desaparición del referido arrocabe que hoy aparece como parte del muro encalado del edificio, en cuyo interior se disponen los estribos en los que encajan los tirantes ${ }^{10}$. Estos sí siguen la definición tradicional andaluza y perfectamente descrita en el texto del contrato.

Con respecto a la armadura de par y nudillo, la novedad más apreciable se encuentra en el ornamento del almizate. Éste en su desarrollo presenta tres zonas cuadradas de lacería, dos en los extremos y uno en el centro. Los dos primeros siguen un esquema de lazo regular, compuesto por una trama en cuadrícula formada por estrellas y aspillas. Más bella y rica es la central que, con este mismo formato, presenta una composición más vistosa y decorativa, ya que recoge una rueda de lacería centrada por una estrella de ocho puntas que a la vez es cubierta por un racimo o piña de mocárabes, todo ello enmarcado por una banda de crucetas. Una estructura y un ornamento que en general sigue un esquema tradicional en la armadura mudéjar sevillana de los siglos XVI y XVII, como se puede comprobar en los ejemplares del convento de Santa Paula, de la iglesia de Santa Catalina, y de San Esteban, todos en la capital hispalense ${ }^{11}$. Sin tampoco olvidar su parentesco con otras obras de su entorno más inmediato, como la armadura de la nave central de la parroquia de Ardales, cuya carpintería presumiblemente también fue realizada en algún taller sevillano en esta misma época ${ }^{12}$.

Pero además de esta cubierta, existe en el templo otra armadura que pudo ser realizada por este mismo artista o quizás por alguno de los que participaron en la subasta ${ }^{13}$. Nos referimos a la que cubre el presbiterio [3], quizás techado antes que la nave, como era tradicional en la evolución constructiva de estos templos para con ello poder iniciar el culto, aunque en este caso no tuviese mucho fundamento. $Y$ lo creemos así por las reducidas dimensiones de la iglesia, además de intuirse en las condiciones cierta indefinición a la hora de establecer de manera concreta lo que se pretendía techar. Como ya expresamos antes, se desprende de la declaración sobre el templo que se desconocían las medidas exactas de la superficie que debía ser cubierta, dándose libertad al carpintero para que, una vez in situ, pudiera plan-

\footnotetext{
10 El templo fue reformado y ampliado en 1695. CAMACHO, R.: Málaga Barroca: arquitectura religiosa de los siglos XVII y XVIII. Op. cit., 1981, pág. 504; Esta misma opinión fue expuesta por AGUILAR, M. D.: Málaga Mudéjar..., op.cit., pág. 172.

11 DUCLOS BAUTISTA, G.: Carpintería de lo blanco en la arquitectura religiosa de Sevilla. Sevilla, Diputación de Sevilla, 1992, págs. 188-203.

12 AGUILAR, M.D.: Málaga Mudéjar..., op.cit., pág. 172.

13 Obra además que para 1588 estaba totalmente concluida ya que en este año estaba también finalizado el retablo mayor realizado por Juan de Oviedo, LÓPEZ MARTíNEZ, C.: Desde Jerónimo Hernández hasta Martínez..., op. cit., pág. 85-86.
} 


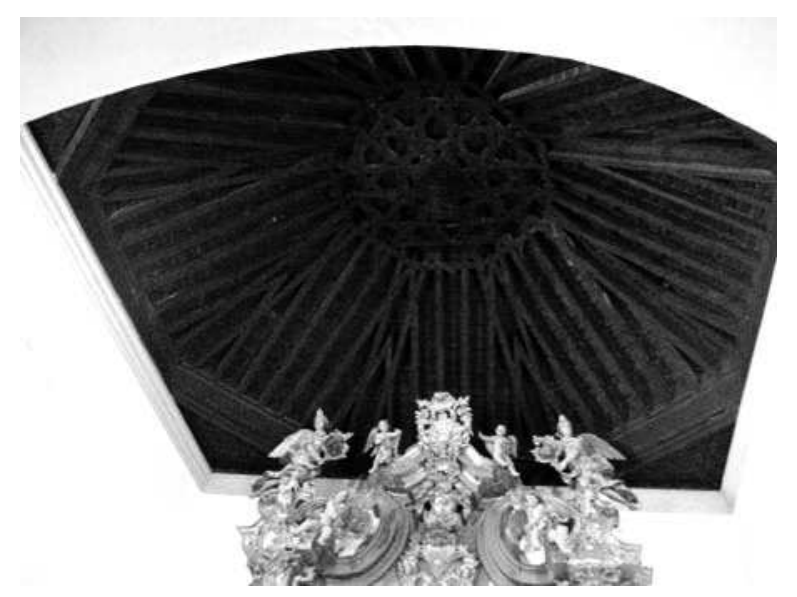

3. Techumbre del presbiterio de la parroquia de la Inmaculada Concepción de Almargen. Atribuida a Juan Bautista, hacia 15601570.

tear alguna modificación de lo pactado, cambio que pudo producirse por la necesidad de cubrir el presbiterio ${ }^{14}$.

Y de hecho, lo que es evidente, sin duda, es su parentesco con la armadura anterior, al igual que con otras de la capital hispalense ${ }^{15}$. Analizando pues esta obra, ahora la solera originaria ha sido sustituida por un moldurón barroco de mampostería sobre el que campean el replano y el arrocabe que en su desarrollo van a definir el octógono donde se asientan los pares de la armadura. Gracias a ello se crean los cuadrantes triangulares, limitados por los tirantes de los lados y el cuadral en ángulo y cuyo paño horizontal se cubre de lacerías ${ }^{16}$. Éstas describen medios signos estrellados de donde parten aspillas, ochavillos y otros elementos, creando unos peculiares entrelazos de ocho. La armadura se desarrolla con los tradicionales pares que se van a unir en las limas de las aristas del prismático octogonal resultante, creando así una trama que va a fundirse en el almizate que cierra la misma. Aquí se dibuja una bella composición de rueda octogonal, en la que partiendo de una estrella de ocho puntas se va generando toda una serie de figuras geométricas en simétrica disposición, concretamente dos coronas de ocho azafates, más otra que se

\footnotetext{
14 De hecho, como dijimos las medidas establecidas eran de 21 metros de largo por 7,5 de ancho, y la nave mide 23,5 de largo por los 7,5 de ancho aproximadamente.

15 Por ejemplo los artesonados del Salón del Príncipe de los Reales Alcázares y del Salón del Pretorio de la Casa de Pilatos, TOAJAS ROGER, M.A.: Diego López de Arenas. Carpintero, alarife y tratadista en la Sevilla del siglo XVII, Sevilla, Diputación de Sevilla 1989, pág. 46, lám. 1.

16 Estas partes al igual que el resto de esta armadura están en mal estado, AGUILAR, M. D.: Málaga Mudéjar..., op. cit., pág.182.
} 
duplica para enlazar con los paños pendientes, además de todo un repertorio de almendrillas y candilejos, aspillas y costadillos, siguiendo lo más tradicional de estos diseños. $Y$ al igual que sucedía en las decoraciones del almizate de la nave, en el centro, cubriendo el signo de ocho, cuelga una gruesa piña de mocárabes. Último detalle ornamental, que al igual que el resto de la lacería, pueden delatar una misma paternidad, la del susodicho carpintero sevillano del que, por lo demás, nada más conocemos de su quehacer artístico $^{17}$.

En otro orden de cosas, sin duda muchas más noticias tenemos del platero cordobés Francisco de Alfaro, nuestro segundo protagonista. A este orfebre de reconocida valía, que vivió y trabajó en la capital

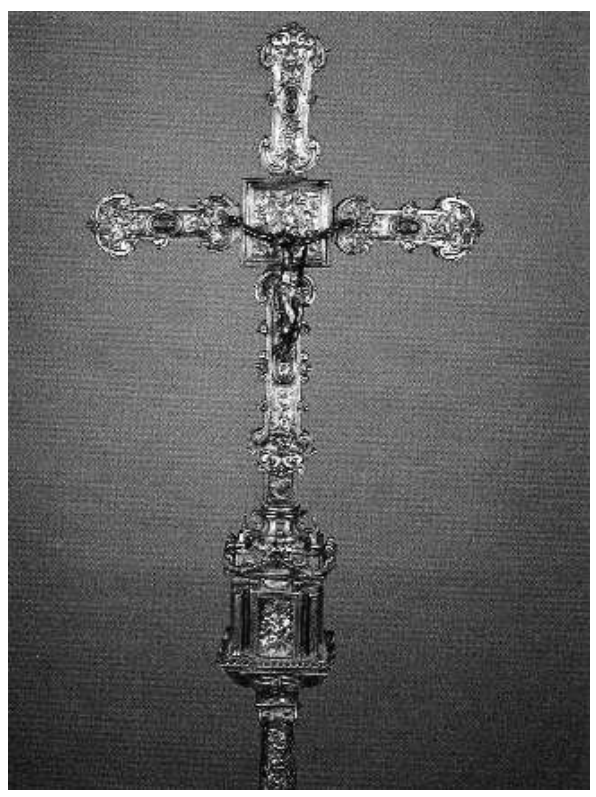

4. Cruz procesional de la parroquia de la Santa Cruz de Teba. Francisco de Alfaro, hacia 1585. hispalense durante el último cuarto del siglo XVI acaparando gran parte del mercado civil y eclesiástico, siempre se le vinculó con la cruz procesional conservada en la iglesia parroquial de Teba [4] ${ }^{18}$. Las razones estilísticas que se venían argumentando para afianzar dicha hipótesis, ahora vienen a ser ratificadas por la documentación que presentamos en este artículo, ya que, a pesar de no ser el concierto de esta obra, se pone en relación por primera vez al maestro platero con esta villa malagueña. Pero para comprender el documento que presentamos, debemos tener en cuenta asimismo la relación que el orfebre tuvo con la vecina ciudad de Antequera. De hecho, su hermana Isabel de Alfaro se había desposado con un antequerano, el platero de oro Juan Bautista de Baena, en 1575. Este matrimonio se había trasladado allí en 1585, siendo el lugar donde fallecen hacia $1590^{19}$. Y por esta vecindad antequerana de su cuñado, el 24 de enero de 1586, Francisco lo apodera para que cobre los maravedíes que le adeu-

\footnotetext{
17 No hemos localizado en la documentación conocida sobre la carpintería de lo blanco sevillana ninguna referencia a este maestro en concreto. GESTOSO, J.: Ensayo de un diccionario de los artífices que florecieron en Sevilla desde el siglo XIII al XVIII inclusive. Sevilla, 1899, t. I, págs.52-72; TOAJAS ROGER, M.A.: Diego López de Arenas..., op. cit., págs. 269-271.

18 Sobre Francisco de Alfaro y su vinculación con la cruz procesional de Teba destacan los estudios de TEMBORY, J.: La orfebrería religiosa en Málaga, Málaga, 1954, págs. 139-142; SANCHEZ LAFUENTE, R.: El Arte de la Platería en Málaga 1550-1800. Málaga, Universidad de Málaga, 1997, págs. 183-186.

19 En ese año, Francisco se hace cargo de sus hijas, Dorotea e Hipólita, a las que desposará con sus dis-
} 
daba la fábrica de la parroquia de la Santa Cruz de Teba20. Desafortunadamente no se especifica la cuantía ni tampoco la razón de esta demanda, pero no es difícil imaginar que una vez entregada la cruz, su cuñado se encargase de otorgar las cartas de pago pertinentes de los maravedíes que por su trabajo recibiría en estos años. Más cuando, sí tenemos la documentación exacta de una obra hermana a ésta de Teba que viene a determinar sin duda su autoría. Concretamente, el 24 de enero de 1585, a petición de Alfaro era tasada por el marcador Cristóbal de Espinosa la cruz de plata de la iglesia de San Bartolomé de Carmona en 28 marcos, 5 onzas y 7 ochavas, una obra que tanto en estructura como en escultura es casi idéntica a la que estamos estudiando21. Por lo tanto, unos años antes al referido 1586 , tuvo que acontecer el encargo de esta pieza clave en la consolidación del manierismo romanista en la platería andaluza.

Otro de los grandes de la platería sevillana de esta época también realizó una obra para esta misma localidad malagueña. Nos referimos al platero de la Catedral hispalense Hernando de Ballesteros el Mozo, a quien, el 30 de octubre de 1590, se le encargó la hechura de una cruz de plata para el monasterio de San Francisco de Teba22. Concretamente el concierto lo hacía con el fraile Francisco de Estrada, el cual le pedía que acabara la pieza para la Pascua de Navidad de este mismo año y que le pagaría por la plata y la hechura empleada 120 ducados, dándole ahora Francisco Martín, en nombre del padre franciscano, los primeros 50 ducados, y posponiendo el resto a la tasación de su creación. Una obra que desgraciadamente ha desaparecido, aunque pudo parecerse mucho a la que en este mismo año el platero entregaba a la parroquia de Mairena del Aljarafe que afortunadamente sí se conserva ${ }^{23}$.

Finalmente, el último trabajo inédito que presentamos es una creación de bordado encomendada a Miguel de Peñaranda, uno de los maestros bordadores más sobresalientes y destacados de la Sevilla de fines del siglo XVI y primer tercio de la centuria siguiente 24 . En concreto se trata del concierto que este bordador firmó con

cípulos Francisco de Alfaro y Oña y Juan de Ledesma Merino. Todos los datos de la familia antequerana de Alfaro se pueden consultar en SANTOS MÁRQUEZ, A. J.: "La vida y la obra de Francisco de Alfaro y Oña (1572-1602)", Laboratorio de Arte 17, Sevilla, 2004, págs. 413-429; "Juan de Ledesma Merino (h. 1572 1632), platero de la Catedral de Sevilla", en RIVAS CARMONA, J. (coord.): Estudios de Platería, San Eloy 2005, Murcia, Universidad de Murcia, 2005, págs. 505-523.

20 AHPSe. SPNSe.: Legajo 7389, oficio 12, libro $1^{\circ}$ de 1586, fol. 279 recto. Documento $2^{\circ}$.

21 AHPSe. SPNSe.: Legajo 6788, oficio 11, libro $1^{\circ}$ de 1585, fol. 320 recto. Además, la doctora María Jesús Mejías ya había dado a conocer con anterioridad datos relativos al pago por esta misma pieza a Francisco de Alfaro. MEJÍAS ÁLVAREZ, M. J.: Orfebrería Religiosa en Carmona. Siglos XV-XIX. Carmona, Ayuntamiento de Carmona, 2000, págs. 226-227.

22 AHPSe. SPNSe.: Legajo 10839, oficio 17. libro $1^{\circ}$ de 1595, fols. 243 vuelto-244 recto. Documento $3^{\circ}$. Esta obra y documento no la incluimos en nuestro trabajo sobre este orfebre debido a que fue localizado después de su publicación. Además el documento se encuentra deshojado e inserto en un legajo que no le corresponde. SANTOS MÁRQUEZ, A. J.: Los Ballesteros. Una familia de plateros en la Sevilla del Quinientos. Sevilla, Diputación de Sevilla, 2007.

23 Ibídem., págs. 162-164.

24 TURMO, I.: Bordados y bordadores sevillanos (siglos XVI a XVIII), Sevilla, Laboratorio de Arte, 1955, págs. $50-52$. 
el Provisor del Arzobispado para la confección y bordado de un velo de difuntos destinado al ajuar litúrgico de la iglesia parroquial de San Sebastián de Cañete la Real, fechado el 27 de junio de 1597, y en el que además se constituía como su fiador el escultor y arquitecto Juan de Oviedo y de la Bandera 25 . El paño de difuntos debía ser de terciopelo negro y llevar bordados dos frisos perimetrales, uno alto y otro bajo, enmarcados por retorchas en oro llano, y en ambos casos con motivos ornamentales inspirados en repertorios clásicos, como cartones recortados en oro matizado y frutos en sedas polícromas, todo perfilado a punto de hábito con seda carmesí. Dicho bordado a la fecha del concierto ya lo tenía realizado sobre un lienzo, como era lo habitual, y en él había utilizado el bordador hilos de oro en torzales redondos, aumentados en algunos casos con medias trenzas, además de utilizar también hilo de plata. Por ello se comprometía a pasarlo al referido terciopelo que pondría la fábrica malagueña, pagándole ésta por todo su trabajo 110 ducados, 50 se los entregaban en este mismo momento y el resto cuando acabase el trabajo, fijado para finales de diciembre de este mismo año. Además, se establecía la premisa que podría variar su precio en función del veredicto de los tasadores, nombrando el bordador para esta finalidad a su compañero de profesión y amigo Sebastián de Sicilia. Paño mortuorio que desgraciadamente tampoco se conserva, aunque presentaría bordados parecidos a los que muestran prendas de la época con esta misma función lúgubre, como los ternos de difuntos de la iglesia de Santa María de Écija y de la parroquia de San Juan de Marchena26.

\section{APÉNDICE DOCUMENTAL:}

Documento $1^{\circ}$.

Sevilla, 1569, marzo, 13 y 21.

Concierto de la armadura de la nave central de la parroquia de la Inmaculada Concepción de Almargen por el carpintero Juan Bautista.

AHPSe. SPNSe.: Legajo 118, oficio 1 , libro $2^{\circ}$ de 1569, ff. 878 vuelto-879 recto.

"Sepan cuantos esta carta vieren como yo Juan Bautista carpintero vecino de esta ciudad de Sevilla en la collacion de San Marcos como principal e yo Pedro Alonso carpintero su hermano vecino que soy desta dicha ciudad de Sevilla en la collacion de San Marcos como su fiador e principal pagador e sin que contra el se haga excursion ni diligencia alguna ambos de mancomun e a voz de uno e cada uno de nos por si e por el todo renunciando la ley de douvoreis de vendi y el bene-

25 AHPSe. SPNSe.: Legajo 3549, oficio 5, libro de 1597, ff. 418 recto-419 vuelto. Documento $4^{\circ}$.

26 TURMO, I.: Bordados..., op. cit., pág. 119; RAVÉ, J. L.: Arte Religioso en Marchena. Siglos XV al XIX, Sevilla, Junta de Andalucía, 1986, pág. 28. 
ficio de la division otorgamos y conocemos que somos convenidos y concertados con el llustrisimo Señor Provisor de Sevilla y con Lazaro Martin de Coca mayordomo mayor de las fabricas de las iglesias de esta ciudad y su arzobispado que estan ausentes en la manera que seamos obligados de hacer en la iglesia de la villa de Almargen de este Arzobispado la obra de carpinteria incluida en unas condiciones el tenor de las cuales es este que sigue:

Aquí las condiciones.

En el nombre de Jesucristo amen. En domingo trece dias del mes de marzo del año del señor de mil e quinientos e sesenta e nueve años en presencia del muy Ilustre Señor Dean e Provisor estando en las casas de audiencia e de su morada juntados muchos hombres oficiales carpinteros después de haber leído las condiciones siguieron se hicieran las bajas que al fin de ellas se contienen.

Esta es una obra de carpintería que manda hacer el muy llustre señor don Cristóbal de Padilla dean y canónigo en la Santa Iglesia de Sevilla y provisor de ella y su Arzobispado en sede bacante y la obra es en la iglesia de la villa de Almargen veinte y una legua de esta dicha ciudad de Sevilla y la obra es una nave del medio que tiene de ancho nueve varas y de largo veinte y seis poco mas o menos la cual dicha obra se declarara por estas condiciones.

- Primeramente el maestro carpintero que esta dicha obra tomare que en una pieza que le sera mostrada que es la nave de la dicha iglesia que tiene de ancho nueve varas poco mas o menos y de largo veinte y seis quedandole las paredes enrasadas suba y asiente todos los nudillos que cupieren a vara de medir uno de otro echando a cada rincon el suyo asi por una banda como por otra y les haga sus picaduras e moscas para en que trave el yeso y los ponga a peso y cordel para que el maestro albañil los apriete y dandoselos apretados suba y clave unas soleras asi por una banda como por otra y estas soleras an de tener una ochava de grueso y una cuarta de ancho y por las frentes les abra una misma moldura romana con sus dos filetes y luego un replano tan ancho como una pulgada y en este replano la abra un dentellon tanto en lleno como en vacio y a todas estas soleras a su por una banda como por otra les de una pulga de buelo mas para el encalado y las deje bien clavadas y bien ajustadas donde ubiere juntas y bien derechas como les conviene a buena obra.

- Item el maestro que esta dicha obra tomase que encima de estas soleras con todo el largo de ellas que es desde el arco toral hasta el mojinete suba y reparta todos los pares de tirantes doblados que cupieren a dos baras de medir una de otra echando a cada cabo una sencilla y a cada par de tirantes le eche seis peinasos dos en medio y dos a cada cabo y las guarnesca de lazo de ocho por esta orden echando en medio un sino y a cada cabo sus dichos medios sinos y cada tirante ha de hacer cuatro safates y las guarnesca de sus aspillas y alibas y tabicas y ochavillos y vayan perfiladas con seis perfiles que aten arromo y agudo y las embarrote por la parte alta y les abra sus galabernas a cola de milano y les deje muy bien guarnecidas y bien acabadas como les conviene y al dicho repartimiento 
y encima unos cercos estribos de bigas de roble labradas por has y canto y los engalaberne en las tirantes a media madera echando en cada pierna dos clavos palmares y desta manera deje todo este telar muy bien clavado y bien desalabeado como lo conviene a buena obra.

- Ytem el maestro que esta obra tomare a de hacer y subir encima de este telar todo de cabo a cabo una armadura de par y nudillo y su hilera y esta dicha armadura a de ir armada al cartabon diatimbon y el nudillo al tercio y perfilada con sus perfiles y en marbatada arromo y agudo y les meta las sierras para las tabicas y eche cada alfarda una de otra una tercia y a este repartimiento clave esta dicha armadura abajo en el cerco y arriba en la hilera y la deje muy bien clavada y bien asentada y a peso y plomo y no remada y la guarnesca de tabicas asi por una banda como por otra y las desboçe y las deje bien parejas.

- Yten el maestro que esta obra tomare que encima de esta dicha armadura asi por los costados como almisate suba y reparta una guarnicion de sinta y saetino al repartimiento que haga haldetas cuadradas echando sus medios sintas sobre las tabicas y quiebras del nudillo y guarnezca toda esta dicha armadura de saetinos asi costados como almisate echando a cada saltino dos clavos y desta manera la deje muy bien guarnesida y muy bien clavada y encima suba y clave todas las tablas que hubiere de menester labradas y acepilladas para cobijas echando a cada tabla enfrente de donde viniere el alfarda tres clavos y desta manera deje toda esta armadura muy clavada de todas las cobijas que hubiere de menester asi por una banda como por otra y almasate todo de cabo a cabo y de la quiebra arriba lo entable de tablas toscas sacadas de hilo y los sancos de abajo asimismo y le eche su almarbate y aliser que haga arrocabe dandole el cuesto que le conviene asi por la una banda como por la otra y deje toda esta armadura muy bien fecha y muy bien acabada.

- Yten el maestro carpintero que esta dicha obra tomare sea obligado a labrar y labre toda la madera de esta armadura las alfardas y tirantes y nudillos a escuadra y codales y juntada y acepillada y les de los marcos que les conviene a buena obra y segun el hueco de la dicha nave y toda la guarnición de sintas y saltinos las labra a un grueso y las sintas a un ancho dandole ancho y grueso que le conviene y la atorre y asepille y las cobijas las acepille y desta manera dejara esta dicha armadura muy labrada y muy acepillada y si alguna cosa queda por olvidose por no mirar que hasta dicha armadura le conviene lo haga sin pedillo por demasía no innovando cosa alguna de ella ni sacándola de su sustancia.

- Yten es condición que el maestro que esta dicha obra tomare desalabe los pinos y los aguile para que los aserradores los asierren y toda la aserreria francesa que fuere de menester para acabar esta dicha obra la pagara la dicha fabrica y toda la demas aserreria que se ha de acordar y tasar será a costa del dicho oficial que la dicha obra tomare y no hago demasia ninguna porque no se la han de pagar sino se la mandare hacer el señor provisor y la haciere que lea pierda y no alce la mano de ella desde el dia que le dieron dineros y materiales e los ofi- 
ciales so pena que por el dia que faltare pague dos ducados de pena los cuales se le descontaran de los dineros que a de haber por la dicha obra y estos dos ducados seran para la dicha fabrica y otros dos ducados al mayordomo de la dicha fabrica sino le dieren dineros y materiales para hacer y acabar la dicha obra y estos dos ducados serán y desde agora se aplican para el dicho oficial que la dicha obra tomare y ponga el dicho maestro herramientas para hacer y acabar esta dicha obra y sogas para subir las maderas.

- Yten el maestro que esta dicha obra tomare contente de fianzas clamas y abonadas al señor Lazaro Martinez de Coçar mayordomo mayor de las fabricas dentro de diez dias que la dicha obra fuere rematada donde no pague la baja que abajo y mas mil maravedies de pena para el que atrás viniere y así vaya de en uno en otro hasta ser afianzada y sepa el maestro que esta dicha obra tomare la de ir a hacer y acabar en la dicha iglesia y para ella le daran los materiales al pie de la dicha iglesia y obra y alla tiene y le daran para hacer y acabar la dicha obra veinte y cinco docenas de tablas de las de flandes de pino y mas cuarenta y dos pinos y ocho vigas de roble mas madera fuere de menester el dicho maestro la parte en Sevilla en las atarazanas o ribera de ella.

-Yten es condicion que por cuanto no tenemos ni se nos trajo ciertamente el largo de la dicha nave ni el ancho es condicion que si hubiere mas cantidad de las veinte y seis varas que estas dichas condiciones dicen y declaran que se le pague todo lo demas que hubiere sueldo a rata como la obra fuere rematada y si tuviere de menos se le descuente al precio que tomo la dicha obra.

- Yten los maravedíes por que se rematare esta dicha obra le daran por esta orden luego como diere fianzas hiciere obligacion le daran el primer tercio fecho el primero tercio le daran y el segundo tercio y fechos los dos tercios le daran la mitad del tercio postrero y fecha y acabada y visitada y dada por buena le acabaran de pagar la dicha obra y la mitad de la visita sera a costa del dicho oficial que la dicha obra tomare y la otra mitad a costa de la dicha fabrica y si alguna cosa estuviere mal lo ha de hacer a su costa y de sus fiadores.

- Yten el maestro que esta obra tomare sera obligado a hacer escritura y dalla sacada al señor Lazaro Martinez de Coçar mayordomo mayor de las fábricas a su costa.

Yten el maestro que esta dicha obra tomare de a Rodrigo Osorio carpintero de las fabricas veinte y cuatro reales paro estas dichas condiciones y nueve al señor San Juesefe y dos reales a Jeronimo de Orbaja notario ante quien se a de hacer el remate que son todos treinta y cinco reales y estos $s$ le han de descontar del primero tercio que le dieren. Puso esta obra con las condiciones sobre dichas Rodrigo Osorio en cincuenta mil maravedíes. LU.

Puso esta obra con las condiciones Miguel de Vallon en cuarenta y cinco mil maravedíes. XLVU.Pusola Cristóbal Jinete en cuarenta mil maravedíes XLU.

Pusola Fernando Vazquez treinta y ocho mil maravedíes XXXVIIIU.

Pusola Juan Bautista en cien ducados XXXVIIU 
Pusola Juan López en treinta y cuatro mil maravedíes XXXIIIIU

Pusola Alonso Hernández en treinta y dos mil maravedíes. XXXIIU

Pusola Miguel de Vallon en treinta mil maravedíes XXXU

Pusola Pedro de Arenillas en veinte y ocho mil maravedíes XXVIIIU.

Pusola Rodrigo Fuente en veinte y siete mil e quinientos XXVIIUd

Pusola Cristóbal Jinete en veinte y siete mil maravedíes XXVIIU

Pusola Juan Bautista en veinte y seis mil maravedíes XXVIU

Pusola Pedro de Arenillas en vente y cinco mil XXVU

Juan Bautista en veinte y cuatro mil maravedíes XXIIIIU.

El señor dean e provisor mando rematar la obra en Juan Bautista carpintero en precio de XXIIIIU maravedíes fiador Pedro Alonso de la Plaza su hermano con las condiciones ordinarias.

La cual dicha obra nos obligamos de hacer desde luego e la continuar e no alzar la mano hasta la dar fecha e acabada conforme a las dichas condiciones e solas partes de ellas e por la dicha obra yo el dicho Juan Bautista he de haber veinte e cuatro mil maravedíes los cuales se me han de pagar conforme a la condición que sobre ello habla y nos obligamos que si no hiciéremos y cumpliéremos la dicha obra que pueda el dicho mayordomo mayor tomar otro que la haga a nuestra costa al precio según e como lo pudieran hacer e hallar e lo que les costare y en ello gastares nosotros seamos obligados a se los pagar e por ello nos pueda dar e ejecutar con solo su juramento o de quien causa suya oviere e damos poder cumplido a las justicias y jueces ante quien esta carta pareciere por que por vivo rigor de derecho e via ejecutoria nos apremien compelan a lo asi pagar e cumplir bien asi como si fuesen contenidos en juicio e fuese sobre ello dada sentencia diferente pase por cosa juzgada e para lo asi pagar e cumplir obligo nuestras personas e bienes abidos e por haber fecha la carta en Sevilla en el oficio de mil el escribano público de esta a que da fe que conozco a los otorgantes lunes veinte e un dias del mes de marzo de mil e quinientos e sesenta y nueve años testigos Antonio de Sotomayor e Juan Pérez de Valderrama escribanos de Sevilla y el dicho Juan Alonso lo firmo de su nombre en el registro porque el dicho Juan Bautista dijo que no saber firmar firmaron por el en el registro los dichos testigos. (correcciones)

(firmas y rúbricas) Juan Alonso, Diego de la Bastida Farfán escribano público de Sevilla, Juan de Valderrama escribano público Juan" 


\section{Documento $2^{\circ}$.}

Sevilla, 1586, enero, 24.

Poder de Francisco de Alfaro platero de masonería a su cuñado Juan Bautista de Baena para que en su nombre pueda pedir demandar y cobrar de la fábrica de la villa de Teba (Málaga) y de su mayordomo los maravedíes adeudados.

AHPSe. SPNSe.: Legajo 7389, oficio 12, libro $1^{\circ}$ de 1586 , fol. 279 recto.

"Sepan cuantos esta carta vieren como yo Francisco de Alfaro platero de mazonería vecino de esta ciudad de Sevilla en la collacion de Santa María otorgo y conozco que doy todo mi poder cumplido cuan bastante de derecho se requiere a Juan Bautista de Baena vecino de esta ciudad de Sevilla especialmente para que por mi y en mi nombre e como yo mismo pueda pedir demandar e recibir e cobrar en jurisdiccion o fuera de el de la fabrica de la villa de Teba e de su mayordomo en su nombre y de quien con derecho deba todas cualesquier contias de maravedíes que me es y fuere obligado a mi pagar por cualesquier mandamiento y otros recaudos o sin ellos y que en cualquier manera me sea debido perteneciente y de lo que reciviere y cobrare pueda dar e otorgar sus cartas de pago finiquito e lo mismo las otorgase y renuncias si fuere necesario la elevacion de los dos años y de la pecunia como en ella se contiene y sobre la dicha cobranza si fuere necesario pueda parecer y parezca ante cualesquier justicias que con derecho deba y facer y actuar y procesar y pedir y procurar todo cuanto convenga se requiera y deba hacer e que asimismo hncio y hacer podria presente sin en que para todo ello e doy tan cumplido como yo lo tengo conveniente y general administración e con facultad que en cuanto a litigar en juicio ynobumos lo pueda asi nombrar otros y a todos reliebo según derecho e para firmeza de ello obligo mi persona e bienes abidos e por haber fecha la carta en Sevilla en el oficio de mi el escribano publico susoescrito doy fe que conozco al dicho otorgante el cual en este registro firmo de su nombre a veinte y quatro dias del mes de enero de mil y quinientos y ochenta y seis años testigos Lorenzo de Villacorta e Francisco Ruiz escribanos de Sevilla.

(Firmas) Joan de Velasco escribano público de Sevilla, Francisco de Alfaro, Lorenzo de Villacorta escribano de Sevilla, Francisco Ruiz escribano de Sevilla" 
Documento $3^{\circ}$.

Sevilla, 1590, octubre, 30.

Concierto de Hernando de Ballesteros con el convento de San Francisco de Teba para hacer una cruz para dicho monasterio.

AHPSe. SPNSe.: Legajo 10839, oficio 17 , libro $1^{\circ}$ de 1595 , fols. 243 vuelto-244 recto.

"Sepan cuantos esta carta vieren como yo Fernando de Ballesteros platero de mazoneria vecino de esta ciudad de Sevilla en la collacion de Santa María otorgo y conozco que soy convenido y concertado con el padre Frey Francisco de Estrada de la orden del Señor San Francisco en nombre del monasterio y convento del señor San Francisco de la villa de Teba que esta presente en tal manera que yo sea obligado e me obligo de dar fecha y acabada a vista de oficiales que de ello sepan para el día de pascua de navidad que venidera de este año en que estamos de la fecha de esta carta una cruz de plata de la traza y modelo y dibujo contenida en la muestra que queda en poder del dicho padre Fray Francisco de Estrada Rubricada de su rubrica y de la mia e por la plata y hechura de la dicha cruz se me han de pagar ciento y veinte ducados en reales en esta manera los cincuenta ducados de ellos que ahora me da e paga el dicho padre fray Francisco de Estrada por mano de Francisco Martin y yo de las recibo realmente e con efecto en reales de plata que ellos valen en presencia de escribano público de Sevilla e testigos de ella y los setenta ducados restantes se me han de pagar luego como haya fecho e acabada la dicha cruz e la aya visto los oficiales que de los dichos cincuenta ducados me doy por pagado a mi voluntad y si para el dicho dia de pascua de navidad de este año no hubiere fecha y acabada la dicha cruz e fecha y acabada no fuere de la forma e manera contenida en el dicho modelo consiento y fecho bien que el dicho padre fray Francisco de Estrada se pueda concertar con otra persona que la haga o por lo que mas les costare e por los dichos cincuenta ducados que asi tengo recibidos e por veinte mil maravedíes de pena que en el dicho caso me obligo de pagar e por todas las costas y menoscabos que sobre ello se le recrecieren se me pueda ejecutar con solamente su juramento y declaracion del dicho padre fray Francisco de Estrada e de quien su poder del dicho monasterio hubiere en otra para de que el relievo y para la paga e cumplimento de ello doy poder a las justicias de su majestad ante quien esta carta pareciere para que por todo sean remedios y rigores del derecho cuya ejecuta y en otra manera e como por sentencia dicha por mi consentida e pasada en cosa juzgada me ejecuten compelan y apremien a lo no pagar e cumplir como dicho es exem ${ }^{\circ}$ las leyes y derechos de mi favor e la quede sin de la general renunciación e obligo mi persona e bienes avidos e por haber e yo Francisco Albadan escribano público de Sevilla doy que que en mi presencia e de los testigos de esta carta el dicho Fernando de Ballesteros recibio del dicho Francisco Martin los dichos cincuenta ducados en la dicha moneda de reales de plata y quedaron en su poder de que se dio por pagado a su voluntad y el dicho Francisco Martín del monasterio del señor San Francisco de la dicha villa de Teba en que declaro no tener parte ni derecho alguno. Fecha la carta en Sevilla en el oficio de mi el dicho escribano publico que doy fe que conozco a los dichos otorgan- 
tes en este registro $s$ firmaron de sus nombres martes treinta dias del mes de octubre de mil e quinientos noventa años y siendo testigos Francisco de Bastida y Juan Barragan escribanos de Sevilla .

(firma) Fernando de Ballesteros.

Y luego el dicho Francisco Martin dándole a firmar dijo que no sabía escribir a su ruego lo firmaron los testigos de esta carta los dichos escribanos de Sevilla.

(firmas) Francisco Albadan escribano público de Sevilla, Juan Barragán escribano de Sevilla, Francisco de Bastida, escribano de Sevilla.".

\section{Documento $4^{\circ}$.}

Sevilla, 1595, junio, 27.

Concierto del bordador Miguel de Peñaranda para hacer un paño mortuorio destinado a la parroquia de Cañete la Real.

AHPSe. SPNSe.: Legajo 3549, oficio 5, libro de 1597, ff. 418 recto-419 vuelto.

"Sepan cuantos esta carta vieren como yo Miguel de Peñaranda bordador vecino de esta ciudad de Sevilla en la collacion de Santa María como principal obligado e yo Juan de Oviedo escultor vecino de esta ciudad de Sevilla en la collacion de San Salvador como su fiador e principal pagador obligado que salgo e me constituyo del susodicho haciendo como hago de deuda y obligación ajena mia propia e sin que contra el susodicho ni sus bienes ni contra otra persona alguna sea fecha ni se haga escursion ni diligencia alguna de fuero ni de derecho la cual dicho beneficio de ella espresamente renuncio y ambos a dos de mancomun y a voz de uno e cada uno de nos por si e por el todo reconociendo las leyes de la mancomunidad y fianza como en ella se contiene otorgamos e conocemos que yo el dicho Miguel de Peñaranda me obligo de facer un velo de difuntos sobre terciopelo negro bordado de dos frisos uno alto y otro bajo el cual es para la iglesia de Cañete la Real el cual se me encargo por el señor provisor de Sevilla y me obligo de lo hacer conforme a las condiciones siguientes:

Primeramente a de ir en el velo de difuntos sobre terciopelo negro bordado dos frisos uno alto e otro bajo conforme a los propios que yo el dicho Miguel de Peñaranda tengo para el dicho velo labrados los cuales frisos van unos cartones labrados de oro matizado a la greca y los frutos de sedas realzadas de oro y toda la opería de oro llano los dichos frisos están labrados sobre lienzo y se an de asentar sobre terciopelo y perfilarlos de punto de avito de seda carmesí y los lomos y arbejacos e frutos formados de torzal redondo que las hileras de medias trenzas e unas quentas que lleva de torzal redondo de plata a de llevar las retorchas de un lasilla en tomisas paguandas y al lado de las tomisas unos cordeles la de abajo cordeles paguandas de la tomisas y en la de arriba una guarda por la perdea fina $\mathrm{y}$ digo que habiendo esta obra bien fecha y acabada conforme tengo vale ciento y 
dos ducados y que lo que pasare de mas se lo dé de gracia a la iglesia el bordador y si no llegare se le quite y $\mathrm{V}$. M. demandara cincuenta ducados con que dé el velo fecho y acabado y entonces le daran la demasia mandandolo $V$. M. ver y tasar y este el mi parecer en mi ausencia y lo firme de mi nombre Sebastián de Sicilia y digo que se entiende el terciopelo por que lo da la iglesia como visto e constituiere Sebastián de Sicilia.

El cual dicho velo me obligo de facer bien fecho y acabado a vista de oficiales que de ello sepan y lo daremos y entregaremos al mayordomo de la dicha iglesia a quien por el derecho de dicho señor provisor fuere mandado fecho y acabado dentro de seis meses desde la fecha de esta carta y así acabado sea de ver por dos personas versadas en el dicho oficio y lo an de tasar en que no pase de ciento y diez ducados y si pasare la demasía no la tengo de poder pedir y si fuese menos de los dichos ciento diez ducados tanto menos se me ha de pagar y para en cuenta de lo cual se me ha de dar luego cincuenta ducados y lo demás se me ha de pagar acabado que lo aya y ambos a dos principal y fiador debajo de la dicha mancomunidad que fecha tenemos nos obligamos el dicho Miguel de Peñaranda me obligo de hacer el dicho velo bueno y bien fecho como es declarado y darlo acabado dentro del dicho tiempo y si no lo hiciera y entregara a la dicha iglesia se pueda contratar con otra persona que lo haga y acabe por el precio que le pareciere y por los maravedíes que le diere de lo que a mi se me a de dar y por lo que oviere recibido se nos pueda ejecutar (...fórmulas...) fecha esta carta en Sevilla en el oficio de mi el dicho escribano público susoescrito que doy fe que conozco a los dichos otorgantes que lo firmaron de sus nombres a veinte y seis del mes de junio de mil e quinientos e noventa e cinco años testigos Diego Ponce y Gregorio de la Era, escribanos de Sevilla

(firmas y rúbricas) Miguel de Peñaranda, Juan de Oviedo, Diego Fernández, escribano público, Diego Ponce escribano de Sevilla, Gregorio de la Era, escribano de Sevilla." 
